\title{
Differential Movement Synchronous Tracking Control Strategy of Double-Shaking Table System Loading with Specimen
}

\author{
Xiaojun Li $\mathbb{D}$, ${ }^{1,2}$ Juke Wang $\left(\mathbb{D},{ }^{1}\right.$ Fangfang $\mathrm{Li}\left(\mathbb{D},{ }^{1} \mathrm{Na} \mathrm{Li}\left(\mathbb{D},{ }^{1}\right.\right.$ and Haohua Huang ${ }^{1}$ \\ ${ }^{1}$ College of Architectural and Civil Engineering, Beijing University of Technology, Beijing 100124, China \\ ${ }^{2}$ Institute of Geophysics, China Earthquake Administration, Beijing 100081, China \\ Correspondence should be addressed to Xiaojun Li; beerli@vip.sina.com
}

Received 1 December 2017; Revised 11 February 2018; Accepted 27 February 2018; Published 2 April 2018

Academic Editor: Mario Terzo

Copyright (c) 2018 Xiaojun Li et al. This is an open access article distributed under the Creative Commons Attribution License, which permits unrestricted use, distribution, and reproduction in any medium, provided the original work is properly cited.

\begin{abstract}
Multisupport, multidimension, and nonuniform excitation seismic experiments have new requirements for shaking table array system in synchronous tracking control. Therefore, this article proposed a novel synchronous tracking strategy, differential movement synchronous tracking control (DMSTC) strategy, for double-shaking table system while taking the interaction between shaking tables and specimen into consideration. DMSTC Simulink model of the double-shaking table with specimen was established and simulations were conducted in various conditions. The results demonstrate the viability of the proposed DMSTC in that the frequency bandwidth of the double-shaking tables is expanded from $3.27 \mathrm{~Hz}$ to $64.57 \mathrm{~Hz}$, the maximum value of differential movement synchronous error is decreased from $1.682 \mathrm{~mm}$ to $0.482 \mathrm{~mm}$, and the maximum tracking errors of the two shaking tables decrease from $1.138 \mathrm{~mm}$ to $0.044 \mathrm{~mm}$ and from $1.030 \mathrm{~mm}$ to $0.497 \mathrm{~mm}$, respectively.
\end{abstract}

\section{Introduction}

Electrohydraulic shaking table is a piece of the most important test equipment for replicating actual vibration situations in seismic tests and many other applications [1-6]. Multisupport, multidimension, and nonuniform excitation experiments have new requirements for shaking table array system in synchronous tracking control [2, 7-9]. Seismic tests of such large-span structures as bridges, dams, railways, pipelines, and so on should consider the traveling wave effect, partial coherent effect, and local site effect to accurately simulate their motion in earthquake. Therefore, synchronous tracking control strategy has become increasingly important and is in need of further development.

The common synchronous control strategies are the parallel control, the master/slave control, the virtual-shaft control, the cross-coupling control, the relative coupling control, adjacent cross-coupling control, ring coupling control, and so on [10-18]. Koren initially proposed the crosscoupling control [12], which, yet, is difficult to be applied to more than two systems. To overcome this limitation, Perez-Pinal et al. proposed the relative coupling control which has stronger synchronous performance and better development $[13,14]$. To reduce the complexity of multiple motor synchronization control systems, the adjacent crosscoupling control strategy and ring coupling control strategy were proposed by researchers $[15,16]$.

To improve synchronous control precision, the control algorithms are also further studied by researchers, such as traditional PID control, adaptive feed forward control, $H \infty$ control, iterative learning control, sliding mode control, fuzzy control, and neural network control [10, 11, 17-25]. Sun and Chiu developed a nonlinear control algorithm to address the motion synchronization of a dual-cylinder electrohydraulic lifting system [23]. Chen et al. proposed an integrated fuzzy controller design that consisted of a pair of cylinder controllers and a motion synchronization controller for synchronous motion and positioning in a hydraulic lifting system [24]. The proposed fuzzy control design effectively handled complex, ill-defined, and uncertain systems. In addition, Liu proposed an intelligent proportional-integralderivative (PID) algorithm based on back propagation (BP) neural network arithmetic for a three-motor system and obtained satisfactory synchronous decoupling control [25]. 
A typical synchronization control scheme consists of synchronization control parameters, synchronization control strategy to calculate the parameters errors, and a control algorithm to improve synchronization control precision. C. Chen and L. Chen classified it into three types of control mode: position mode, velocity mode, and torque mode [20]. Tsuruta et al. considered motor torsion, displacement, and speed to improve the stability and synchronous control precision of the studied system [26, 27]. Moreover, Zhang et al. focused on the deviation of the array displacement, speed, and acceleration parameters of shaking tables to elevate the synchronous properties of the system [6]. Fang et al. utilized a synchronous control strategy that combined phase-shifting and amplitude-varying methods to achieve the synchronous motion of two parallel servos [28].

Many studies demonstrate that the feedforward compensator control is an effective method to improve a system's synchronous tracking accuracy. Zhang et al. applied the adaptive inverse control (AIC) algorithm to two shaking tables' synchronous tracking controls to improve the tracking precision [6]. In addition, a fuzzy tracking controller (FTC) was designed by Chen et al. to reduce the position-tracking error caused by the parameter uncertainties and nonlinearities of the hydraulic components [24].

However, to date, there are few synchronous tracking control researches in shaking table system with the consideration of the interaction between the specimen and the shaking table system. Particularly, the study of differential movement synchronous tracking control is rare. Therefore, a mathematical model of the double-shaking table system with specimen was built in this research; and the shaking table system of Beijing University of Technology (BJUT) was taken as the research object to verify the synchronous tracking strategy of the DMSTC for shaking table's motion, thereby establishing a Simulink model of the DMSTC. In this paper, the double-shaking table system was described in Section 1, and the hydraulic system was established in Section 2. Subsequently, the mathematical model of the double-shaking table system with specimen was established and the Simulink model of the DMSTC was presented in Section 3, and the simulation analysis was conducted in Section 4. Finally, in Section 5, a brief conclusion of the paper was given.

\section{System Description}

2.1. Introduction of the Double-Shaking Table System. The system of nine subarray shaking tables, composed of nine single shaking tables of $1 \mathrm{~m} \times 1 \mathrm{~m}$, can be used in shaking table's array experiments with diversified forms and in various positions. Figure 1 shows the structure of the double-shaking table system. Each single shaking table is composed of platform, supporting guide mechanism, servo valves, hydraulic cylinders, connecting rod, and base. As the core control unit, the servo valves use small control current to control the flow of high pressure oil. The hydraulic cylinders, as the force transform unit, can impose huge force on the platform through the supporting guide mechanism. Each system, with hydraulic cylinders and servo valves, has three

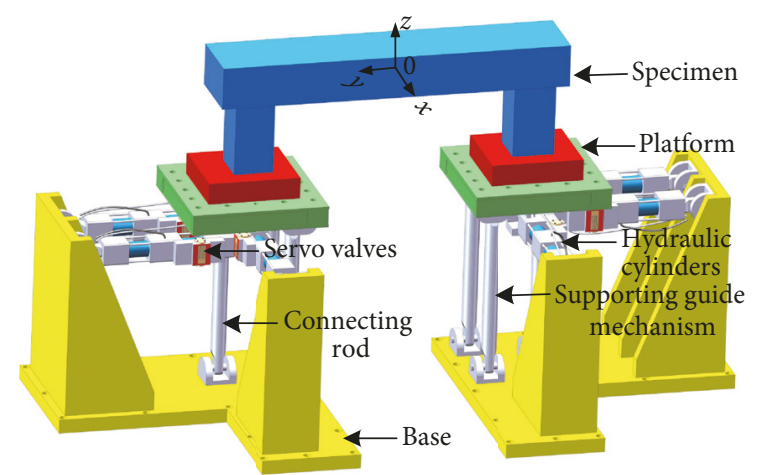

FIGURE 1: The structure diagram of the double-shaking table system with specimen.

exciters, one in $X$ direction and two in $Y$ horizontal direction, and three connecting rods in $Z$ vertical direction.

2.2. The Establishment of the Hydraulic Cylinder Model. The hydraulic system is composed of the hydraulic cylinder, the servo valve, pressure sensor, energy accumulator, and so on. The hydraulic system can be presented in a series of difference equations in the establishment of shaking table's dynamic model. As the core component of shaking table, the servo valve's property is critical for the motion of shaking table.

2.2.1. The Servo Valve Model. The servo valve model can be established with the basis of the second-order oscillation link:

$$
G_{q}(s)=\frac{K_{v}}{s^{2} / w_{v}^{2}+\left(2 \xi_{v} / w_{v}\right) s+1},
$$

where $w_{v}$ is the inherent frequency of the servo valve, $\xi_{v}$ is the damping ratio of the servo valve, and $K_{v}$ is the flow gain of the servo valve.

2.2.2. The Continuity Equations of Hydraulic Cylinder. Assuming that damping and spring effect are not involved in the hydraulic cylinder system [29], the continuity equations of hydraulic cylinder are

$$
\begin{aligned}
Q_{L} & =k_{q} G_{q} E-K_{C} p_{L}, \\
A_{p} p_{L} & =M \frac{d^{2} x_{p}}{d t^{2}} \\
Q_{L} & =A_{p} \frac{d x_{p}}{d t}+\frac{V}{4 \beta} \frac{d p_{L}}{d t}+C_{C} p_{L},
\end{aligned}
$$

where $Q_{L}$ is represented as load flow, $k_{q}$ is flow gain of slid valve near static operation point, $G_{q}$ is servo value transfer function, $E$ is control error signal, $K_{C}$ is flow pressure parameter of slid valve near static operation point, $p_{L}$ is load pressure, $A_{p}$ is effective bearing area of valve, $M$ is the gross mass of valve and its load deduction, $x_{p}$ is displacement of valve, $V$ is gross capacity of two hydraulic cylinder chamber, $\beta$ is oil elastic modulus, and $C_{C}$ is gross leakage coefficient of hydraulic cylinder. 
Regarding the platform and specimen as an integrity, and load property as inertial load, the continuity equations of hydraulic cylinder can be obtained after the processing of Laplace transform. They are shown as follows:

$$
\begin{aligned}
M s^{2} x & =A_{p} p_{L}, \\
Q_{L} & =A_{p} s x+\frac{V}{4 \beta} s p_{L}+C_{C} p_{L}, \\
Q_{L} & =k_{q} G_{q} E-K_{C} p_{L} .
\end{aligned}
$$

\section{The DMSTC Model of the Double-Shaking Table System with Specimen}

3.1. The Deduction of the Interaction between the DoubleShaking Tables and Specimen. Figure 2 shows the simplified mechanical model of the double-shaking table system with specimen. $M_{1}$ and $M_{2}$ are the masses of the two platforms, respectively, and $M_{1}=M_{2}=M_{T} ; x_{1}$ and $x_{2}$ are their displacements; $F_{1}$ and $F_{2}$ are exciting forces of their hydraulic systems; $M_{S}$ is the mass of the specimen; $x_{S}$ is the specimen's displacement; $C$ is the specimen's damping coefficient; and $K$ is the specimen's stiffness coefficient.

The force equilibrium equations are

$$
\begin{aligned}
& M_{S} s^{2} x_{S}+(C s+k)\left(x_{s}-x_{1}\right)+(C x+k)\left(x_{s}-x_{2}\right)=0, \\
& M_{1} s^{2} x_{1}+(C s+k)\left(x_{1}-x_{s}\right)=F_{1}, \\
& M_{2} s^{2} x_{2}+(C s+k)\left(x_{2}-x_{s}\right)=F_{2} .
\end{aligned}
$$

Then

$$
\begin{aligned}
& {\left[M_{S} s^{2}+2(C s+k)\right] x_{s}-(C x+k) x_{1}-(C s+k) x_{2}} \\
& \quad=0 \\
& \left(M_{1} s^{2}+C s+k\right) x_{1}-(C s+k) x_{s}=F_{1}, \\
& \left(M_{2} s^{2}+C s+k\right) x_{2}-(C s+k) x_{s}=F_{2} .
\end{aligned}
$$

The force equilibrium equations are

$$
\begin{aligned}
& A_{p} p_{L 1}=F_{1}, \\
& A_{p} p_{L 2}=F_{2} .
\end{aligned}
$$

Presuming that the parameters of the two exciters are the same, the output flow of salve valves is

$$
\begin{aligned}
& Q_{L 1}=k_{q} G_{q} E_{1}-K_{C} p_{L 1}, \\
& Q_{L 2}=k_{q} G_{q} E_{2}-K_{C} p_{L 2} .
\end{aligned}
$$

The flow of exciters is

$$
\begin{aligned}
Q_{L 1} & =A_{p} s x_{1}+\frac{V}{4 \beta} s p_{L 1}+C_{C} p_{L 1}, \\
Q_{L 2} & =A_{p} s x_{2}+\frac{V}{4 \beta} s p_{L 2}+C_{C} p_{L 2} .
\end{aligned}
$$

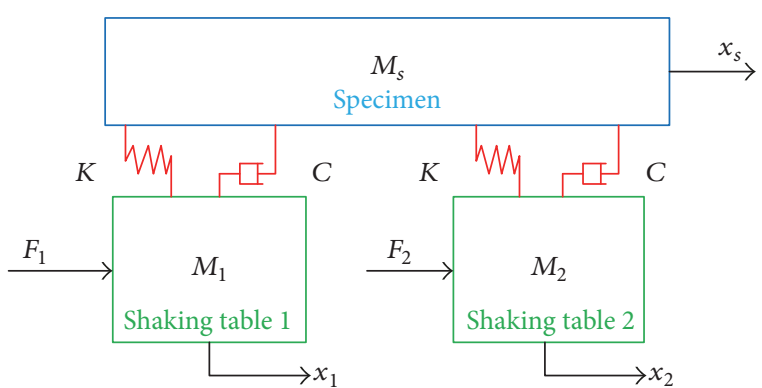

FIGURE 2: Simplified mechanical model.

Equalizing (5) and (6), the result is

$$
\begin{aligned}
& \left(\frac{V}{4 \beta} s+K_{C}+C_{C}\right) p_{L 1}=k_{q} G_{q} E_{1}-A_{p} s x_{1}, \\
& \left(\frac{V}{4 \beta} s+K_{C}+C_{C}\right) p_{L 2}=k_{q} G_{q} E_{2}-A_{p} s x_{2} .
\end{aligned}
$$

Given

$$
G_{2}=\frac{V}{4 \beta A_{P}^{2}} s+\frac{K_{C}+C_{C}}{A_{p}^{2}},
$$

then

$$
\begin{aligned}
& A_{p} p_{L 1}=\frac{1}{G_{2}}\left(\frac{k_{q} G_{q} E_{1}}{A_{p}}-s x_{1}\right), \\
& A_{p} p_{L 2}=\frac{1}{G_{2}}\left(\frac{k_{q} G_{q} E_{2}}{A_{p}}-s x_{2}\right) .
\end{aligned}
$$

We substitute (9) into (4) to get

$$
\begin{aligned}
& G_{2}\left(M_{1} s^{2}+C s+k\right) x_{1}-G_{2}(C s+k) x_{s} \\
& \quad=\frac{k_{q} G_{q} E_{1}}{A_{p}}-s x_{1}, \\
& G_{2}\left(M_{2} s^{2}+C s+k\right) x_{2}-G_{2}(C s+k) x_{s} \\
& =\frac{k_{q} G_{q} E_{2}}{A_{p}}-s x_{2} .
\end{aligned}
$$

We simplify (4) to get

$$
x_{s}=\frac{C s+k}{M_{S} s^{2}+2(C s+k)}\left(x_{1}+x_{2}\right) .
$$

The PID control transfer function is

$$
G_{\mathrm{PID}}=K_{P}\left(1+\frac{1}{T_{i} s}+T_{d} s\right) .
$$


We combine (12) and (13) to get

$$
\begin{aligned}
& {\left[G_{2}\left(M_{1} s^{2}+C s+k\right)+s-\frac{G_{2}(C s+k)^{2}}{M_{S} s^{2}+2(C s+k)}\right] x_{1}} \\
& -\frac{G_{2}(C s+k)^{2}}{M_{S} s^{2}+2(C s+k)} x_{2}=\frac{G_{q} k_{q} E_{1}}{A_{p}}, \\
& {\left[G_{2}\left(M_{2} s^{2}+C s+k\right)+s-\frac{G_{2}(C s+k)^{2}}{M_{S} s^{2}+2(C s+k)}\right] x_{2}} \\
& -\frac{G_{2}(C s+k)^{2}}{M_{S} s^{2}+2(C s+k)} x_{1}=\frac{G_{q} k_{q} E_{2}}{A_{p}} .
\end{aligned}
$$

We take the displacement feedback gain, PID control transfer function, and the displacement meter transfer function into consideration to get

$$
\begin{aligned}
& E_{1}=G_{\mathrm{PID}} u_{1}-G_{d} K d x_{1}, \\
& E_{2}=G_{\mathrm{PID}} u_{2}-G_{d} K d x_{2} .
\end{aligned}
$$

We write (16) into (15) to get

$$
\begin{aligned}
& {\left[G_{2}\left(M_{1} s^{2}+C s+k\right)+s-\frac{G_{2}(C s+k)^{2}}{M_{S} s^{2}+2(C s+k)}\right.} \\
& \left.+\frac{G_{q} k_{q}}{A_{p}} G_{d} K d\right] x_{1}-\frac{G_{2}(C s+k)^{2}}{M_{S} s^{2}+2(C s+k)} x_{2} \\
& =\frac{G_{\mathrm{PID}} G_{q} k_{q} u_{1}}{A_{p}} \\
& {\left[G_{2}\left(M_{2} s^{2}+C s+k\right)+s-\frac{G_{2}(C s+k)^{2}}{M_{S} s^{2}+2(C s+k)}\right.} \\
& \left.+\frac{G_{q} k_{q}}{A_{p}} G_{d} K d\right] x_{2}-\frac{G_{2}(C s+k)^{2}}{M_{S} s^{2}+2(C s+k)} x_{1} \\
& =\frac{G_{\mathrm{PID}} G_{q} k_{q} u_{2}}{A_{p}} \text {. }
\end{aligned}
$$

Given

$$
\begin{aligned}
G_{3}= & G_{2}\left(M_{T} s^{2}+C s+k\right)+s-\frac{G_{2}(C s+k)^{2}}{M_{S} s^{2}+2(C s+k)} \\
& +\frac{G_{q} k_{q}}{A_{p}} G_{d} K d, \\
G_{4}= & \frac{G_{2}(C s+k)^{2}}{M_{S} s^{2}+2(C s+k)},
\end{aligned}
$$

then

$$
\begin{aligned}
& G_{3} x_{1}-G_{4} x_{2}=\frac{G_{\mathrm{PID}} G_{q} k_{q} u_{1}}{A_{p}}, \\
& G_{3} x_{2}-G_{4} x_{1}=\frac{G_{\mathrm{PID}} G_{q} k_{q} u_{2}}{A_{p}} .
\end{aligned}
$$

Finally, the system transfer functions can be obtained:

$$
\begin{aligned}
& x_{1}=\frac{G_{\mathrm{PID}} G_{q} k_{q}}{A_{p}} \frac{G_{3} u_{1}+G_{4} u_{2}}{G_{3}{ }^{2}-G_{4}{ }^{2}}, \\
& x_{2}=\frac{G_{\mathrm{PID}} G_{q} k_{q}}{A_{p}} \frac{G_{3} u_{2}+G_{4} u_{1}}{G_{3}{ }^{2}-G_{4}{ }^{2}} .
\end{aligned}
$$

3.2. The Proposition of the DMSC. Figure 3 shows the model of the double-shaking table system in different coordinates of the double-shaking table system, in which the input coordinate system and the output coordinate system were established. In the input coordinate system, $u_{1}$ and $u_{2}$ are input signals and $\phi$ is the desired rotation angle. In the output coordinate system, $x_{1}$ and $x_{2}$ are output signals, $l$ is the distance between the shaking table and the central line of the double-shaking table system, and $\varphi$ is the actual rotation angle of the double-shaking table system.

We substitute (13) into (12) to get

$$
\begin{aligned}
& {\left[G_{2}\left(M_{1} s^{2}+C s+k\right)+s\right] x_{1}} \\
& \quad-\frac{G_{2}(C s+k)^{2}}{M_{S} s^{2}+2(C s+k)}\left(x_{1}+x_{2}\right)=\frac{G_{q} k_{q} E_{1}}{A_{p}}, \\
& {\left[G_{2}\left(M_{2} s^{2}+C s+k\right)+s\right] x_{2}} \\
& \quad-\frac{G_{2}(C s+k)^{2}}{M_{S} s^{2}+2(C s+k)}\left(x_{1}+x_{2}\right)=\frac{G_{q} k_{q} E_{2}}{A_{p}} .
\end{aligned}
$$

Given

$$
\begin{aligned}
& G_{5}=G_{2}\left(M_{T} s^{2}+C s+k\right)+s, \\
& G_{4}=\frac{G_{2}(C s+k)^{2}}{M_{S} s^{2}+2(C s+k)}
\end{aligned}
$$

and writing (22) into (21) to get

$$
\begin{aligned}
& G_{5} x_{1}-G_{4}\left(x_{1}+x_{2}\right)=\frac{G_{q} k_{q} E_{1}}{A_{p}}, \\
& G_{5} x_{2}-G_{4}\left(x_{1}+x_{2}\right)=\frac{G_{q} k_{q} E_{2}}{A_{p}},
\end{aligned}
$$

then

$$
\begin{aligned}
\left(G_{5}-2 G_{4}\right)\left(x_{1}+x_{2}\right) & =\frac{G_{q} k_{q}}{A_{p}}\left(E_{1}+E_{2}\right), \\
G_{5}\left(x_{1}-x_{2}\right) & =\frac{G_{q} k_{q}}{A_{p}}\left(E_{1}-E_{2}\right) .
\end{aligned}
$$

We deduct from the output signal coordinate system of Figure 3 with geometric method to acquire

$$
\begin{aligned}
& x_{1}=x+l \varphi \\
& x_{2}=x-l \varphi
\end{aligned}
$$




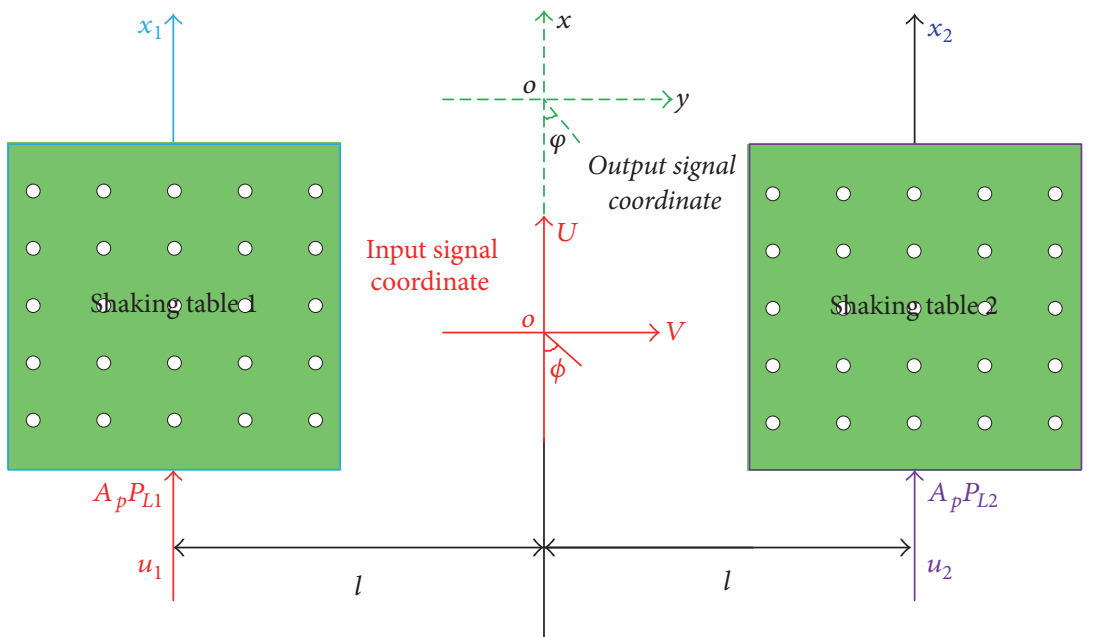

FIGURE 3: The model of the double-shaking table system in different coordinates.

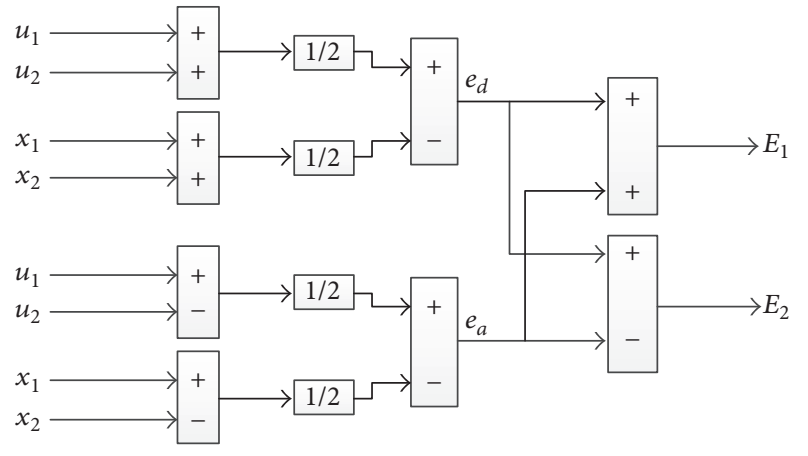

FIGURE 4: Controlling block diagram.

Then

$$
\begin{aligned}
& x_{1}+x_{2}=2 x, \\
& x_{1}-x_{2}=2 l \varphi .
\end{aligned}
$$

We deduct from the input signal coordinate system in Figure 3 to acquire

$$
\begin{aligned}
& u_{1}=u+l \phi, \\
& u_{2}=u-l \phi .
\end{aligned}
$$

Then

$$
\begin{aligned}
& u_{1}+u_{2}=2 u, \\
& u_{1}-u_{2}=2 l \phi .
\end{aligned}
$$

In order to get the control error signal of the doubleshaking table system, the controlling block diagram is designed as shown in Figure 4, in which $e_{d}$ is the translation error and $e_{a}$ is the rotation error.

We deduct from Figure 4 to get

$$
\begin{aligned}
& E_{1}=e_{d}+e_{a}, \\
& E_{2}=e_{d}-e_{a} .
\end{aligned}
$$

Then

$$
\begin{aligned}
& E_{1}+E_{2}=2 e_{d}, \\
& E_{1}-E_{2}=2 e_{a} .
\end{aligned}
$$

We take the displacement feedback gain, PID control transfer function, and the displacement meter transfer function into consideration to get

$$
\begin{aligned}
& e_{d}=\frac{1}{2}\left[G_{\mathrm{PID}}\left(u_{1}+u_{2}\right)-G_{d} K d\left(x_{1}+x_{2}\right)\right], \\
& e_{a}=\frac{1}{2}\left[G_{\mathrm{PID}}\left(u_{1}-u_{2}\right)-G_{d} K d\left(x_{1}-x_{2}\right)\right] .
\end{aligned}
$$

We substitute (26) and (28) into (31) to get

$$
\begin{aligned}
& e_{d}=G_{\mathrm{PID}} u-G_{d} K d x, \\
& e_{a}=G_{\mathrm{PID}} l \phi-G_{d} K d l \varphi .
\end{aligned}
$$

We write (32) into (30) to get

$$
\begin{aligned}
& E_{1}+E_{2}=2\left(G_{\mathrm{PID}} u-G_{d} K d x\right), \\
& E_{1}-E_{2}=2\left(G_{\mathrm{PID}} l \phi-G_{d} K d l \varphi\right) .
\end{aligned}
$$

We write (26) and (33) into (24) to get

$$
\begin{aligned}
\left(G_{5}-2 G_{4}+\frac{G_{q} k_{q}}{A_{p}} G_{d} K d\right) x & =\frac{G_{\mathrm{PID}} G_{q} k_{q}}{A_{p}} u \\
\left(G_{5}+\frac{G_{q} k_{q}}{A_{p}} G_{d} K d\right) \varphi & =\frac{G_{\mathrm{PID}} G_{q} k_{q}}{A_{p}} \phi
\end{aligned}
$$

Equation (34) can be transformed into

$$
\begin{aligned}
& \frac{x}{u}=\frac{G_{\mathrm{PID}} G_{q} k_{q}}{A_{p}} \frac{1}{G_{5}-2 G_{4}+\left(G_{q} k_{q} / A_{p}\right) G_{d} K d}, \\
& \frac{\varphi}{\phi}=\frac{G_{\mathrm{PID}} G_{q} k_{q}}{A_{p}} \frac{1}{G_{5}+\left(G_{q} k_{q} / A_{p}\right) G_{d} K d} .
\end{aligned}
$$




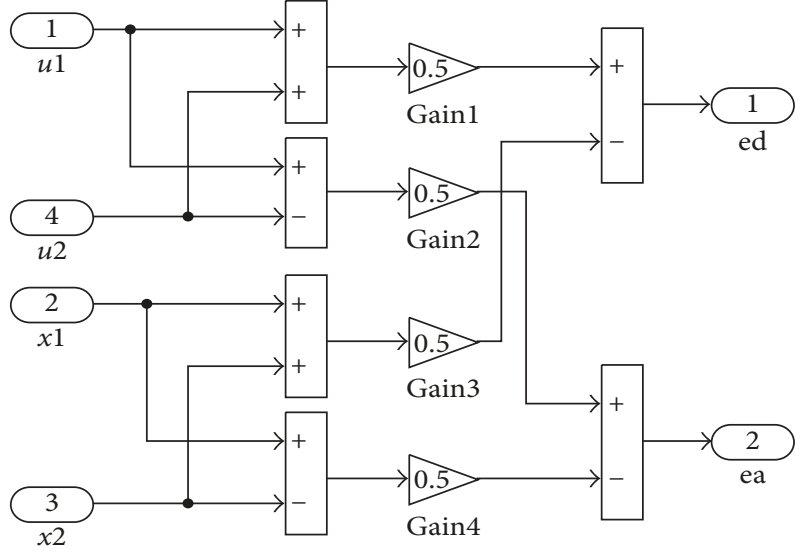

(a) Error processing in detail

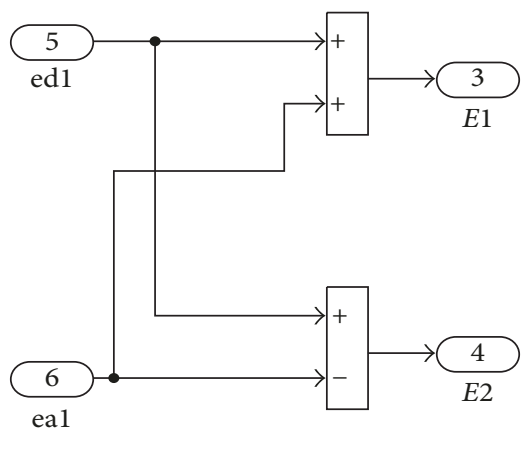

(b) Error coupling in detail

FIgURE 5: Simulink model of the DMSC.

We write (28) and (33) into (24) to get

$$
\begin{gathered}
\left(G_{5}-2 G_{4}+\frac{G_{q} k_{q}}{A_{p}} G_{a} K d\right)\left(x_{1}+x_{2}\right) \\
=\frac{G_{\mathrm{PID}} G_{q} k_{q}}{A_{p}}\left(u_{1}+u_{2}\right), \\
\left(G_{5}+\frac{G_{q} k_{q}}{A_{p}} G_{a} K d\right)\left(x_{1}-x_{2}\right) \\
=\frac{G_{\mathrm{PID}} G_{q} k_{q}}{A_{p}}\left(u_{1}-u_{2}\right) .
\end{gathered}
$$

Given

$$
\begin{aligned}
& G_{6}=G_{5}-2 G_{4}+\frac{G_{q} k_{q}}{A_{p}} G_{d} K d, \\
& G_{7}=G_{5}+\frac{G_{q} k_{q}}{A_{p}} G_{d} K d,
\end{aligned}
$$

then

$$
\begin{aligned}
& x_{1}+x_{2}=\frac{G_{\mathrm{PID}} G_{q} k_{q}}{A_{p} G_{6}}\left(u_{1}+u_{2}\right), \\
& x_{1}-x_{2}=\frac{G_{\mathrm{PID}} G_{q} k_{q}}{A_{p} G_{7}}\left(u_{1}-u_{2}\right) .
\end{aligned}
$$

Finally, the system's transfer function can be acquired:

$$
\begin{aligned}
& x_{1}=\frac{G_{\mathrm{PID}} G_{q} k_{q}}{2 A_{p}}\left[u_{1}\left(\frac{1}{G_{6}}+\frac{1}{G_{7}}\right)+u_{2}\left(\frac{1}{G_{6}}-\frac{1}{G_{7}}\right)\right], \\
& x_{2}=\frac{G_{\mathrm{PID}} G_{q} k_{q}}{2 A_{p}}\left[u_{1}\left(\frac{1}{G_{6}}-\frac{1}{G_{7}}\right)+u_{2}\left(\frac{1}{G_{6}}+\frac{1}{G_{7}}\right)\right] .
\end{aligned}
$$

We write (20) and (39) into the form of transfer function matrix as follows:

$$
\left\{\begin{array}{l}
x_{1} \\
x_{2}
\end{array}\right\}=\left[\begin{array}{ll}
H_{11} & H_{12} \\
H_{21} & H_{22}
\end{array}\right]\left\{\begin{array}{l}
u_{1} \\
u_{2}
\end{array}\right\} .
$$

Then the system's transfer functions of double-shaking table system with specimen are

$$
\begin{aligned}
& H_{11}=H 11=H 22=\frac{G_{\mathrm{PID}} G_{q} k_{q}}{A_{p}} \frac{G_{3}}{G_{3}{ }^{2}-G_{4}{ }^{2}}, \\
& H_{12}=H 12=H 21=\frac{G_{\mathrm{PID}} G_{q} k_{q}}{A_{p}} \frac{G_{4}}{G_{3}{ }^{2}-G_{4}{ }^{2}} .
\end{aligned}
$$

Then we apply the DMSC strategy to the double-shaking table system with specimen to get the transfer function:

$$
\begin{aligned}
& H_{11}=G 11=G 22=\frac{G_{\mathrm{PID}} G_{q} k_{q}}{2 A_{p}}\left(\frac{1}{G_{6}}+\frac{1}{G_{7}}\right), \\
& H_{12}=G 12=G 21=\frac{G_{\mathrm{PID}} G_{q} k_{q}}{2 A_{p}}\left(\frac{1}{G_{6}}-\frac{1}{G_{7}}\right) .
\end{aligned}
$$

Equation (35) shows that the displacement and the rotation are independent freedom degrees without coupling. Equation (41) shows the system's transfer functions of doubleshaking table system with specimen. Equation (42) shows the system's transfer functions of double-shaking table system with specimen utilizing DMSC strategy.

The above-mentioned differential movement synchronous control is divided into two parts: error processing and error coupling. The Simulink model is shown in Figure 5.

3.3. The Design of the AIC. In Section 3.2, the DMSC is developed to improve the synchronization precision of the two shaking tables. In this section, this study combined the AIC based on Normalized Least Mean Square (NLMS) algorithm with the proposed synchronous strategy to realize 
TABLE 1: The parameters of the double-shaking table model.

\begin{tabular}{lc}
\hline Parameters & Values \\
\hline Mass of the platform & $1 t$ \\
Bulk modulus of oil & $7 \times 10^{8} \mathrm{~N} / \mathrm{m}^{2}$ \\
Flow coefficient of servo valve pressure & $1.0 \times 10^{-11} \mathrm{~m}^{5} / \mathrm{N} / \mathrm{s}$ \\
Spool flow gain & $6 \times 10^{-3} \mathrm{~m}^{3} / \mathrm{s} \cdot \mathrm{V}$ \\
Inherent frequency of servo valve & $628 \mathrm{rad} / \mathrm{s}$ \\
Leakage coefficient of hydraulic cylinder & $7.5529 \times 10^{-15} \mathrm{~m}^{5} / \mathrm{N} / \mathrm{s}$ \\
Damping ratio of servo valve & 0.7 \\
Effective bearing area of valve & $4.73 \times 10^{-3} \mathrm{~m}^{2}$ \\
Displacement feedback gain & $0.21 \mathrm{~V} / \mathrm{m}^{-3}$ \\
Equivalent volume of cylinder & $3.9023 \times 10^{-3} \mathrm{~m}^{3}$ \\
Damping ratio of sensor & 0.7 \\
Inherent frequency of sensor & $942 \mathrm{rad} / \mathrm{s}$ \\
\hline
\end{tabular}

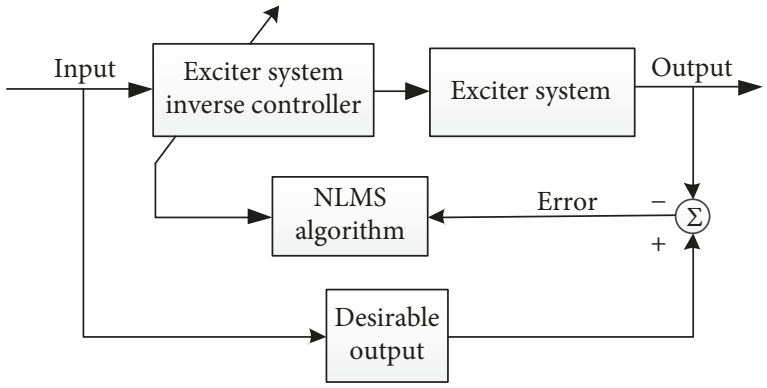

FIgURE 6: The adaptive inverse control system structure of the shaking table.

synchronous tracking control of the double-shaking table system.

As shown in Figure 6, the error signal calculated by the desired signal and the exciter output signal is utilized to adjust the weight coefficient of the controller, thereby realizing the waveform reproduction of the shaking table.

The weight updating formula of the NLMS algorithm is shown as follows:

$$
\begin{aligned}
\mathbf{w}(n+1) & =\mathbf{w}(n)+2 \mu e(n) \mathbf{x}(n), \\
\mu & =\frac{\alpha}{\beta+\|\mathbf{x}(n)\|^{2}},
\end{aligned}
$$

where $\mathbf{w}(n)$ is the weight coefficient of the $N$-rank finite impulse response (FIR) digital filter, $\mu$ is the convergence factor constant, $e(n)$ is the error of the filter, $\mathbf{x}(n)$ is the input signal of the filter, and $\|\mathbf{x}(n)\|^{2}$ is the input signal's Euclidean norm square.

The designed adaptive inverse controller is shown in Figure 7. In this Simulink model, $\alpha=0.25$ and $\beta=0.5$.

\subsection{The Model of the DMSTC}

3.4.1. The Model of the Double-Shaking Table System with Specimen. The model of the double-shaking table system with specimen is shown in Figure 8. Table 1 shows the parameters of the model of the double-shaking table system
TABle 2: The PID control parameters of the double-shaking table system.

\begin{tabular}{lllc}
\hline PID parameters & $K p$ & $K i$ & $K d$ \\
\hline Shaking table & 0.6 & 0.2 & 0.025 \\
\hline
\end{tabular}

and the PID control parameters are shown in Table 2 . According to the hydraulic system model established in Section 2.1 and the deduction of the interaction between the shaking table and the specimen in Section 3.1, the model is established in Matlab/Simulink with the parameters in Table 1. In the simulations, the mass of the specimen is $2000 \mathrm{~kg}$, the frequency is $3 \mathrm{~Hz}$, and the damping ratio is 0.02 .

3.4.2. The Model of the DMSTC. On the ground of the above deduction, analysis, and modeling, a synchronous tracking control system (including the double-shaking table system and specimen, the DMSC block, and the AIC blocks) is established in Matlab/Simulink, as shown in Figure 9.

\section{Results and Discussions}

4.1. The System's Frequency Response Performance. The frequency transform functions (FRFs) of the double-shaking table system without DMSTC and with DMSTC are shown in Figure 10. The frequency bandwidth of the system without DMSTC- $H 11$ is only $3.27 \mathrm{~Hz}$, which leads to different dynamic responses and synchronization error, while the frequency performance of the system with DMSTC-G11 is increased from $3.27 \mathrm{~Hz}$ to $64.57 \mathrm{~Hz}$, which improves the accuracy of the signal representation and reduces the synchronization error simultaneously.

4.2. Random Wave Test. The random waves 1 and 2, which are input into shaking tables 1 and 2, respectively, are shown in Table 3. The results without DMSTC and with DMSTC are shown in Figure 11. For comparative study, the details of Figure 11(b) are enlarged.

Table 4 shows that, with DMSTC, the replication accuracy of each shaking table is improved. For shaking table 1, the 


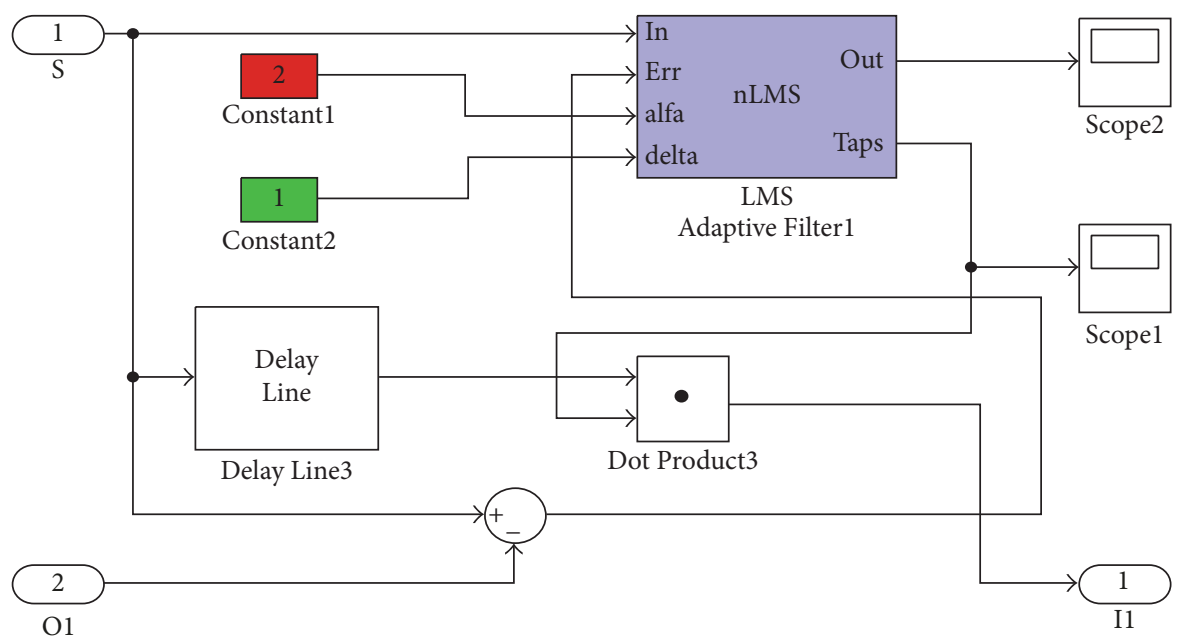

FIGURE 7: The adaptive inverse controller.

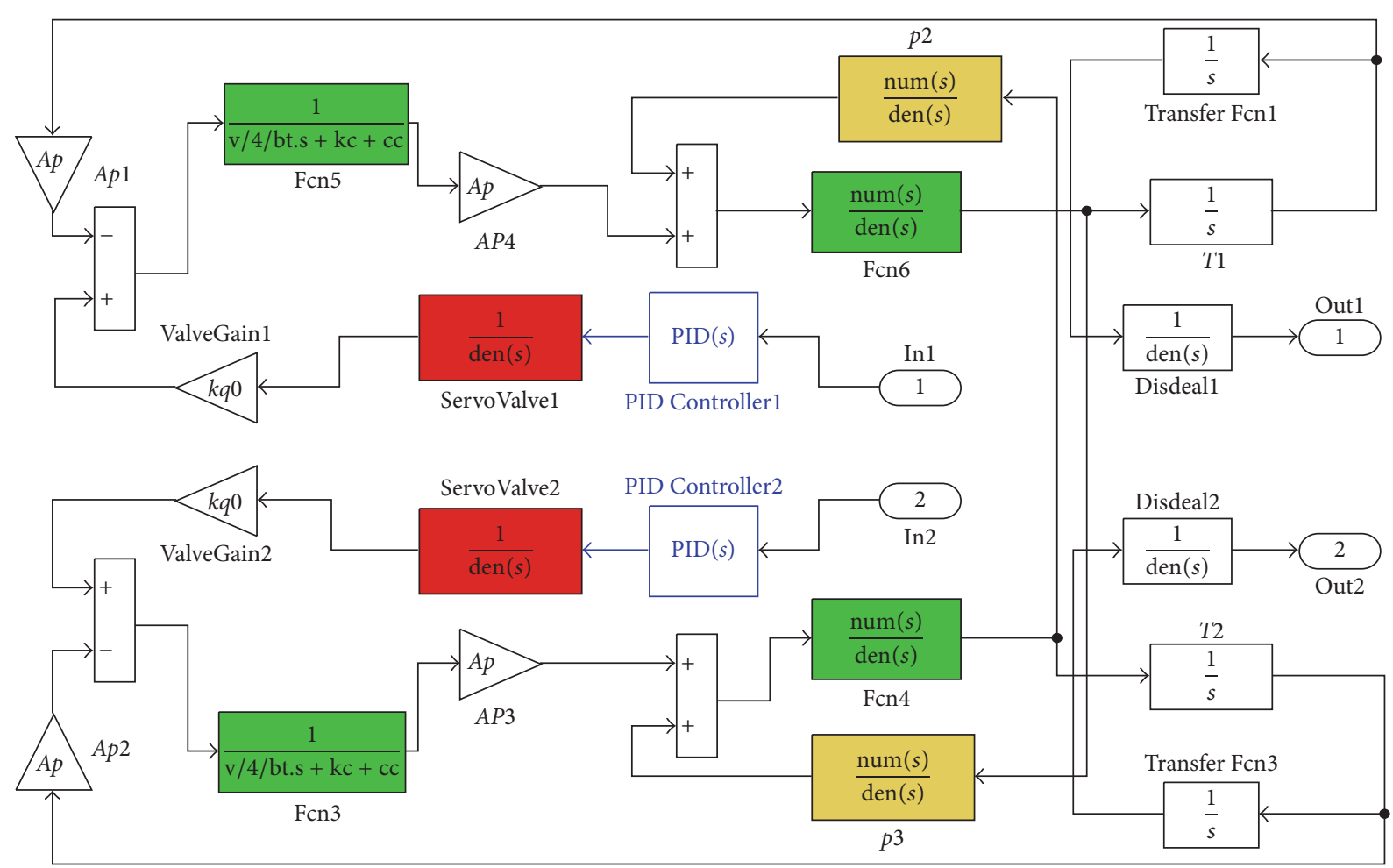

FIgURE 8: The model of double-shaking table system with specimen.

TABLE 3: Different random waves.

\begin{tabular}{lcc}
\hline Wave parameters & Amplitude & Frequency \\
\hline Random wave 1 & $\pm 2.0 \mathrm{~mm}$ & $0.4 \mathrm{~Hz}-5 \mathrm{~Hz}$ \\
Random wave 2 & $\pm 1.0 \mathrm{~mm}$ & $20 \mathrm{~Hz}-40 \mathrm{~Hz}$ \\
\hline
\end{tabular}

correlative coefficient rises from $72.7 \%$ to $99.8 \%$. For shaking table 2 , the correlative coefficient rises from $58.6 \%$ to $82.7 \%$.

Figures 12 and 14 show that, with DMSTC, the tracking accuracy of each shaking table is improved. For shaking table
TABLE 4: Random waves' correlative coefficient of the doubleshaking table system.

\begin{tabular}{lcc}
\hline Shaking table & Without DMSTC & With DMSTC \\
\hline 1 & $72.7 \%$ & $99.8 \%$ \\
2 & $58.6 \%$ & $82.7 \%$ \\
\hline
\end{tabular}

1 , the maximum tracking error, $\max (u 1-x 1)$, decreases from $1.138 \mathrm{~mm}$ to $0.044 \mathrm{~mm}$ and the root mean square tracking error, RMS $(u 1-x 1)$, decreases from $0.454 \mathrm{~mm}$ to $0.017 \mathrm{~mm}$. 


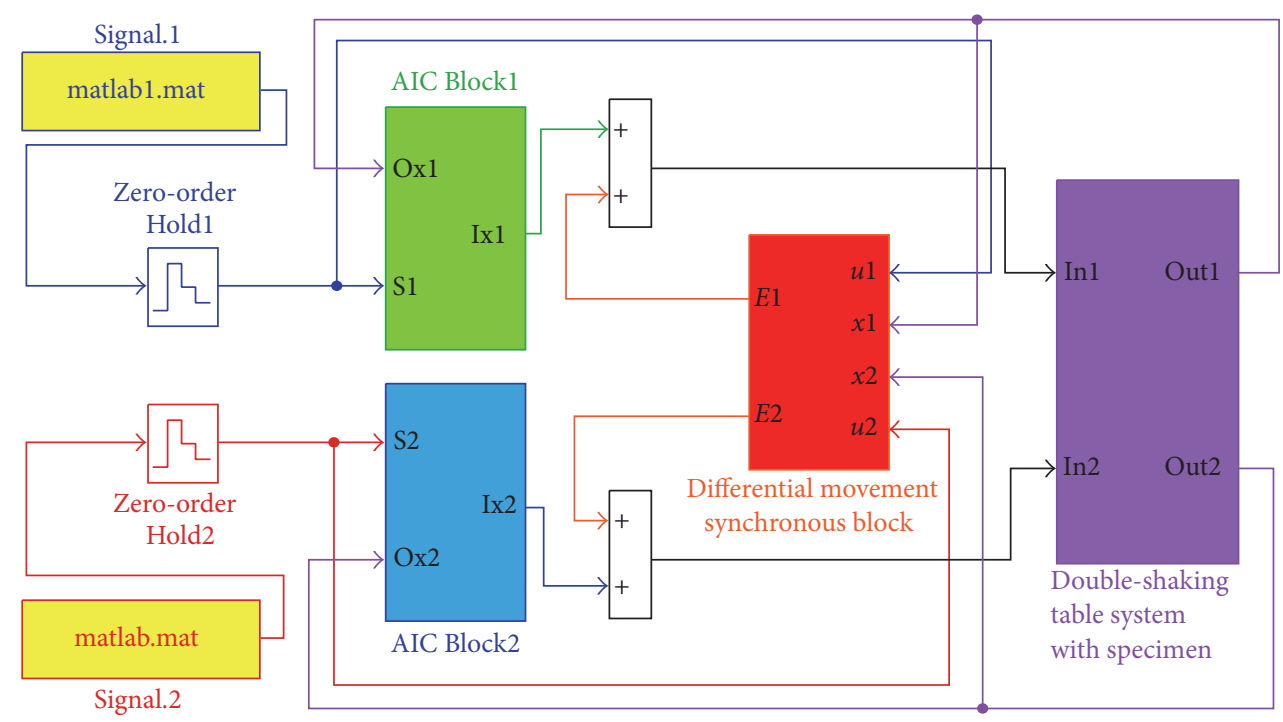

FIGURE 9: The DMSTC model.

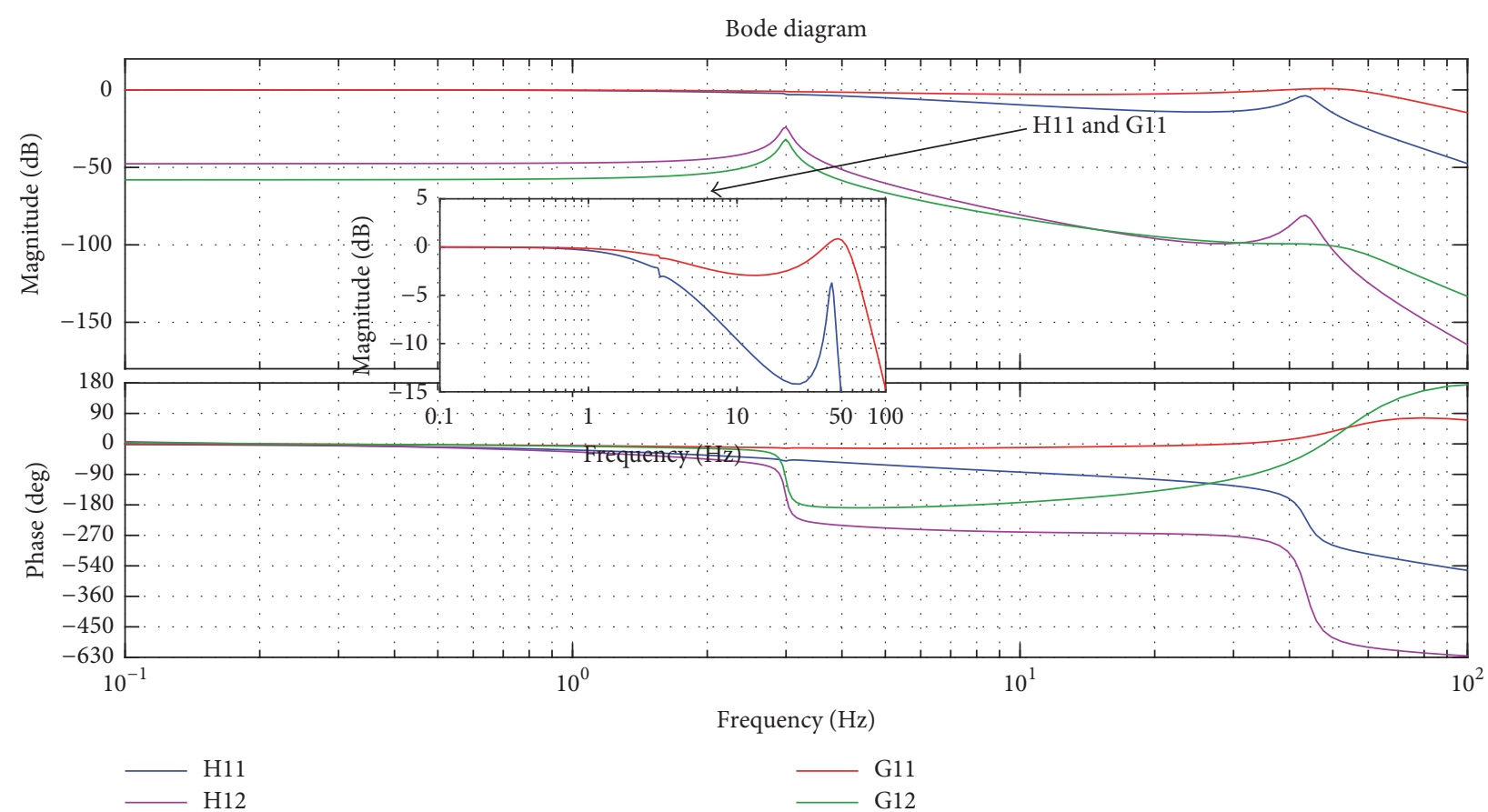

FIGURE 10: The FRFs of the double-shaking table system.

For shaking table 2 , the maximum tracking error, $\max (u 2-$ $x 2$ ), decreases from $1.030 \mathrm{~mm}$ to $0.497 \mathrm{~mm}$ and the root mean square tracking error, RMS $(u 2-x 2)$, decreases from $0.296 \mathrm{~mm}$ to $0.144 \mathrm{~mm}$.

Figures 13 and 14 demonstrate that the differential movement synchronous performance is greatly improved. Namely, the error of the desired deviation and the accurate deviation decreases. The maximum value of the differential movement synchronous error, $\max (E)$, decreases from $1.682 \mathrm{~mm}$ to $0.482 \mathrm{~mm}$, and the root mean square value of the differential movement synchronous error, $\operatorname{RMS}(E)$, decreases from $0.541 \mathrm{~mm}$ to $0.145 \mathrm{~mm}$.

\section{Conclusion}

In conclusion, this research proposed a novel synchronous tracking strategy, DMSTC strategy, for shaking table's motion to generate the control error signals while taking the interaction between shaking tables and specimen into consideration and to improve the system's tracking precision. DMSTC Simulink model of the double-shaking table with specimen was established and simulations were conducted in various conditions. The results of the study are as follows:

(1) The proposed DMSTC strategy extends the doubleshaking table system's frequency bandwidth from $3.27 \mathrm{~Hz}$ to 


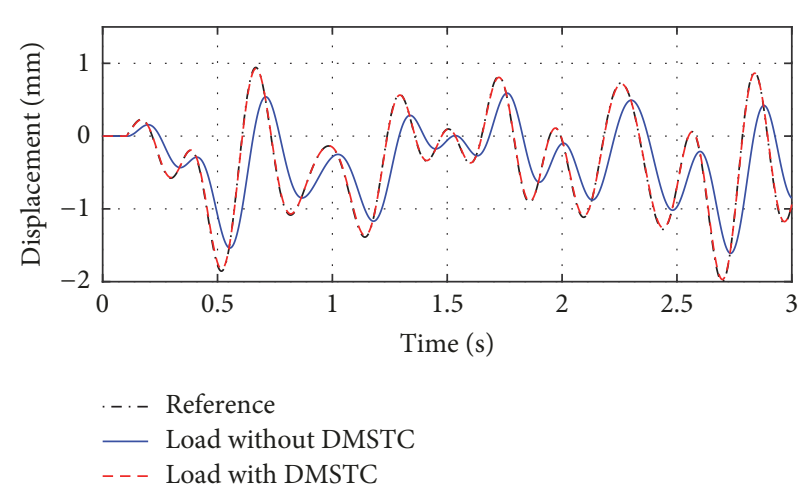

(a) Random wave 1

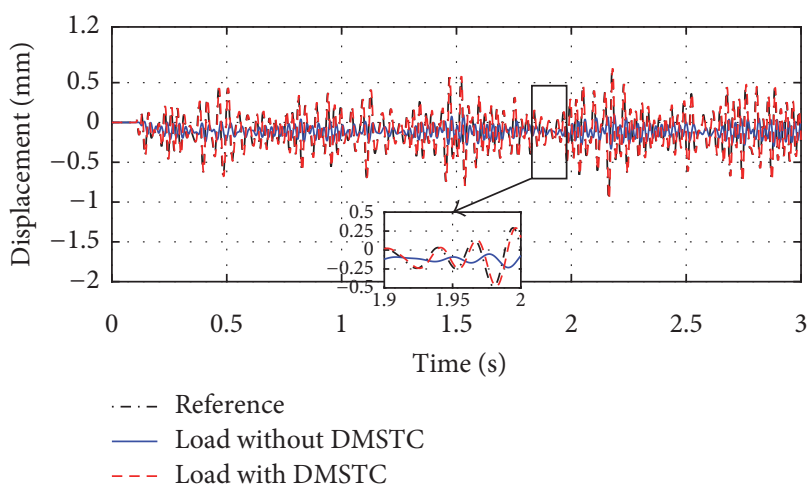

(b) Random wave 2

FIgURE 11: Random wave test.

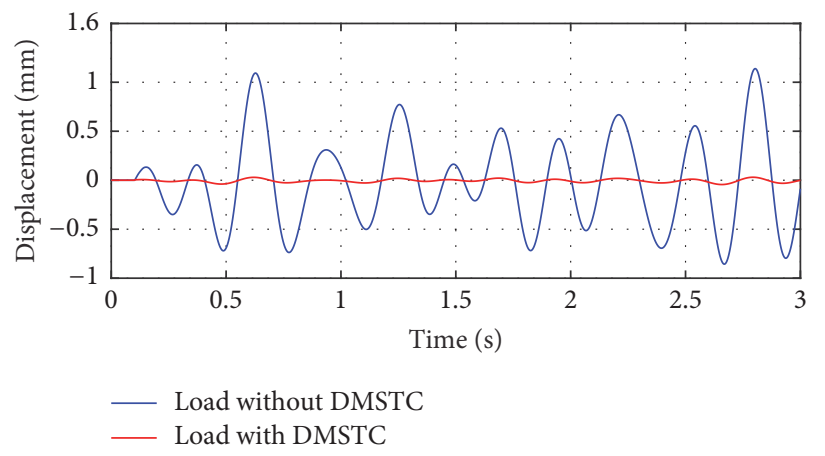

(a) Tracking error of shaking table 1

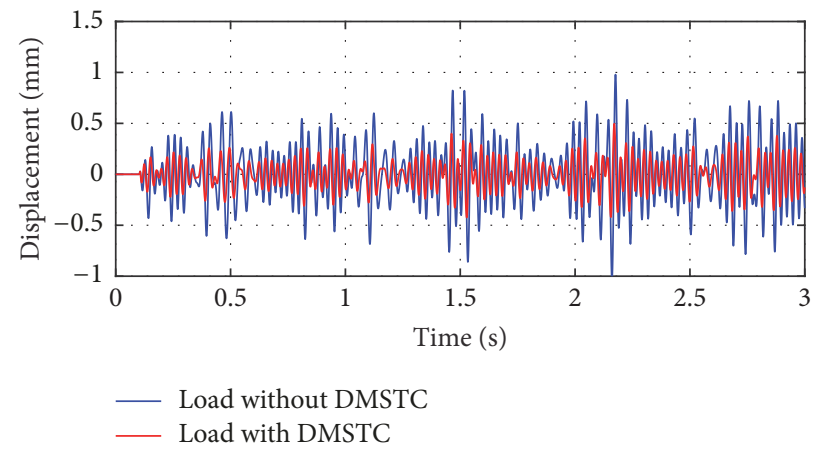

(b) Tracking error of shaking table 2

FIGURE 12: The tracking error of the double-shaking table.

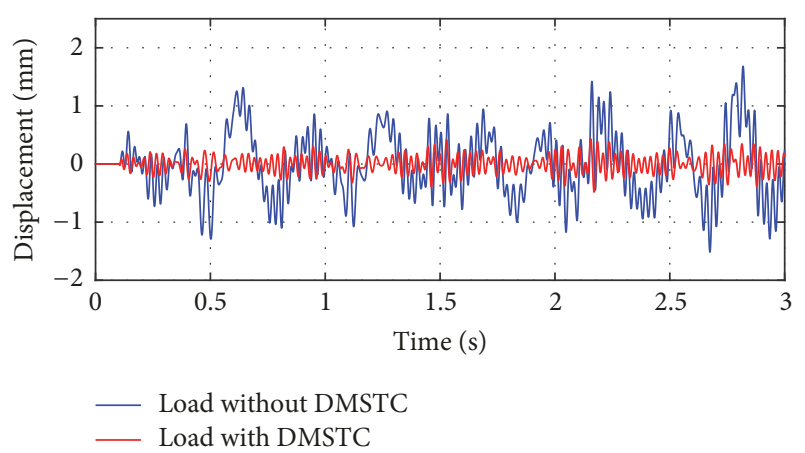

FIGURE 13: The differential movement synchronous error.

$64.57 \mathrm{~Hz}$, which improves the frequency bandwidth of the double-shaking table system.

(2) The replication accuracy of each shaking table is improved. For shaking table 1, the correlative coefficient rises by $27.1 \%$. For shaking table 2 , the correlative coefficient rises from $58.6 \%$ to $82.7 \%$.

(3) The tracking accuracy of each shaking table is improved. For shaking table 1, the maximum tracking error decreases from $1.138 \mathrm{~mm}$ to $0.044 \mathrm{~mm}$. For shaking table 2, the maximum tracking error decreases by $51.74 \%$.

(4) The differential movement synchronous error decreases, the maximum absolute value of that decreases by

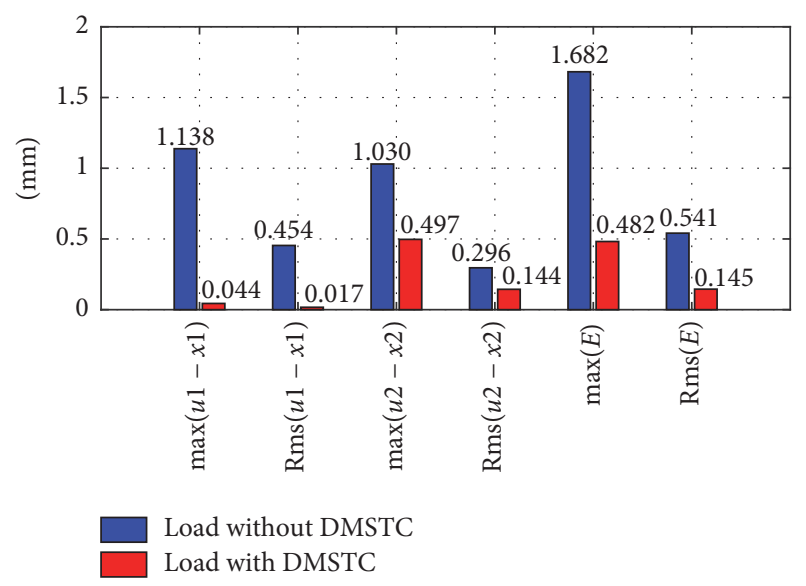

Figure 14: Data analysis of the tracking errors and synchronous error.

$71.34 \%$, and the root mean square value of that decreases by $73.20 \%$.

\section{Conflicts of Interest}

The authors declare that there are no conflicts of interest regarding the publication of this paper. 


\section{Acknowledgments}

This research was supported by the National Natural Science Foundation of China under Grant nos. 51738001, 51508526, and 51421005.

\section{References}

[1] G. Shen, Z.-C. Zhu, X. Li, Y. Tang, D.-D. Hou, and W.-X. Teng, "Real-time electro-hydraulic hybrid system for structural testing subjected to vibration and force loading," Mechatronics, vol. 33, pp. 49-70, 2016.

[2] C. H. Gao, J. B. Ji, W. M. Yan, and N. Li, "Developments of shaking table technology in China," China Civil Engineering Journal, vol. 47, no. 8, pp. 9-19, 2014.

[3] G. Shen, X. Li, Z. Zhu, Y. Tang, W. Zhu, and S. Liu, "Acceleration tracking control combining adaptive control and off-line compensators for six-degree-of-freedom electro-hydraulic shaking tables," ISA Transactions, vol. 70, pp. 322-337, 2017.

[4] G. Shen, S.-T. Zheng, Z.-M. Ye, Q.-T. Huang, D.-C. Cong, and J.W. Han, "Adaptive inverse control of time waveform replication for electrohydraulic shaking table," Journal of Vibration and Control, vol. 17, no. 11, pp. 1611-1633, 2011.

[5] G. Shen, Z. C. Zhu, L. Zhang et al., "Adaptive feed-forward compensation for hybrid control with acceleration time waveform replication on electro-hydraulic shaking table," Control Engineering Practice, vol. 21, no. 8, pp. 1128-1142, 2013.

[6] L. P. Zhang, D. C. Cong, Z. D. Yang et al., "Attitude synchronous tracking control of double shaking tables based on hybrid fuzzy logic cross-coupled controller and adaptive inverse controller," Journal of Intelligent \& Fuzzy Systems, vol. 29, pp. 2537-2546, 2015.

[7] J. B. Ji, F. F. Li, Z. B. Li et al., "Research and advances on the control technology of the multiple shaking table array system," Structural Engineers, vol. 28, no. 6, pp. 96-101, 2012.

[8] J. B. Ji, X. L. Li, and W. M. Yan, "Research on shaking table array and dynamic model test," Structural Engineering International, vol. 27, no. s1, pp. 31-36, 2011.

[9] Z. H. Zong, L. Chen, and Y. Huang, "Research and application of testing technology of the earthquake simulation multiple shaking table facilities," Structural Engineering International, vol. 27, no. s1, pp. 6-14, 2011.

[10] L. Li, L. Sun, and S. Zhang, "Mean deviation coupling synchronous control for multiple motors via second-order adaptive sliding mode control," ISA Transactions, vol. 62, pp. 222-235, 2016.

[11] L.-B. Li, L.-L. Sun, S.-Z. Zhang, and Q.-Q. Yang, "Speed tracking and synchronization of multiple motors using ring coupling control and adaptive sliding mode control," ISA Transactions, vol. 58, pp. 635-649, 2015.

[12] Y. Koren, "Cross-coupled biaxial computer control for manufacturing systems," Journal of Dynamic Systems, Measurement, and Control, vol. 102, no. 4, pp. 265-272, 1980.

[13] F. J. Perez-Pinal, G. Calderon, and I. Araujo-Vargas, "Relative coupling strategy," in Proceedings of the IEEE International Electric Machines and Drives Conference, IEMDC 2003, pp. 1162-1166, Madison, WI, USA, June 2003.

[14] F. Perez-Pinal, C. Nunez, R. Alvarez, and I. Cervantes, "Comparison of multi-motor synchronization techniques," in Proceedings of the 30th Annual Conference of IEEE Industrial Electronics Society, 2004. IECON 2004, pp. 1670-1675, Busan, South Korea.
[15] D. Zhao, C. Li, and J. Ren, "Speed synchronization of multiple induction motors with adjacent cross coupling control," in Proceedings of the 48th IEEE Conference on Decision and Control held jointly with 2009 28th Chinese Control Conference, CDC/CCC 2009, pp. 6805-6810, chn, December 2009.

[16] J. Sun, R. Liu, Y. Luo, and W. Sun, "Research on Multimotor Synchronization Control for Cutter Head of Shield Machine Based on the Ring Coupled Control Strategy," in Intelligent Robotics and Applications, vol. 5928 of Lecture Notes in Computer Science, pp. 345-354, Springer Berlin Heidelberg, Berlin, Heidelberg, 2009.

[17] X. Lai and W. Xie, "Theoretical and Experimental Study on Electromechanical Coupling Properties of Multihammer Synchronous Vibration System," Shock and Vibration, vol. 2016, Article ID 6707264, 11 pages, 2016.

[18] X.-L. Zhang, C.-Y. Zhao, and B.-C. Wen, "Theoretical and experimental study on synchronization of the two homodromy exciters in a non-resonant vibrating system," Shock and Vibration, vol. 20, no. 2, pp. 327-340, 2013.

[19] P. R. Ouyang, T. Dam, and V. Pano, "Cross-coupled PID control in position domain for contour tracking," Robotica, vol. 33, no. 6, pp. 1351-1374, 2015.

[20] C. Chen and L. Chen, "Robust cross-coupling synchronous control by shaping position commands in multiaxes system," IEEE Transactions on Industrial Electronics, vol. 59, no. 12, pp. 4761-4773, 2012.

[21] K. L. Barton and A. G. Alleyne, "A cross-coupled iterative learning control design for precision motion control," IEEE Transactions on Control Systems Technology, vol. 16, no. 6, pp. 1218-1231, 2008.

[22] D. Zhao, S. Li, F. Gao, and Q. Zhu, "Robust adaptive terminal sliding mode-based synchronised position control for multiple motion axes systems," IET Control Theory \& Applications, vol. 3 , no. 1, pp. 136-150, 2009.

[23] H. Sun and G. T.-C. Chiu, "Motion synchronization for dualcylinder electrohydraulic lift systems," IEEE/ASME Transactions on Mechatronics, vol. 7, no. 2, pp. 171-181, 2002.

[24] C.-Y. Chen, L.-Q. Liu, C.-C. Cheng, and G. T.-C. Chiu, "Fuzzy controller design for synchronous motion in a dual-cylinder electro-hydraulic system," Control Engineering Practice, vol. 16, no. 6, pp. 658-673, 2008.

[25] X. Liu, X. Zhang, J. Hu, Y. Liu, G. Liu, and L. Zhao, “Threemotor synchronous decoupling control based on BP neural network," in Proceedings of the 2009 Chinese Control and Decision Conference, CCDC 2009, pp. 5365-5368, Guilin, China, June 2009.

[26] K. Tsuruta, T. Ojiro, and H. Honda, "Synchronization control for twin-axes table drive system," in Proceedings of the 41st Annual Conference of the IEEE Industrial Electronics Society, IECON 2015, pp. 5162-5167, Yokohama, Japan, November 2015.

[27] K. Tsuruta, T. Ojiro, N. Ushimi, and H. Shibata, "Vibration suppression control for multiaxis table drive system," in Proceedings of the 2013 10th IEEE International Conference on Mechatronics and Automation, IEEE ICMA 2013, pp. 1135-1140, Takamatsu, Japan, August 2013.

[28] J. H. Fang, J. H. Wei, and X. W. Kong, "Synchronous control strategy for paralleled servo valves," Journal of Zhejiang University, vol. 46, no. 6, pp. 1054-1059, 2012.

[29] H. H. Huang, Design and application of the shaking table, Seismological Press, Beijing, China, 2008. 


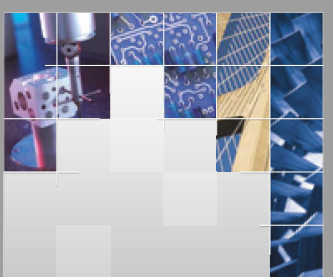

\section{Enfincering}
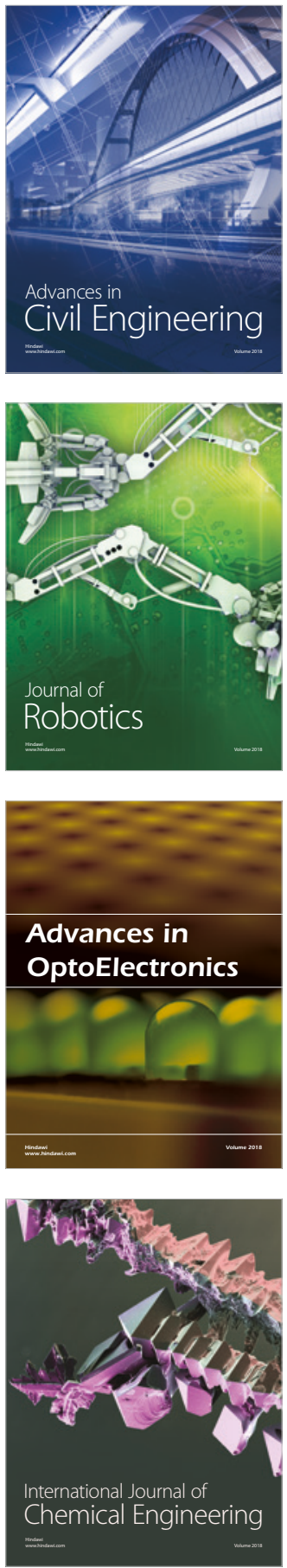

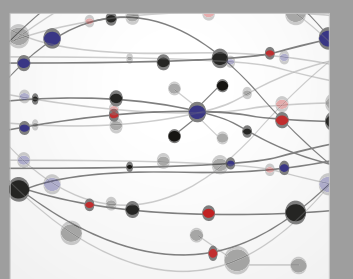

\section{Rotating \\ Machinery}

The Scientific World Journal

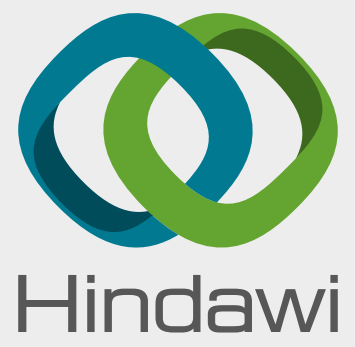

Submit your manuscripts at

www.hindawi.com
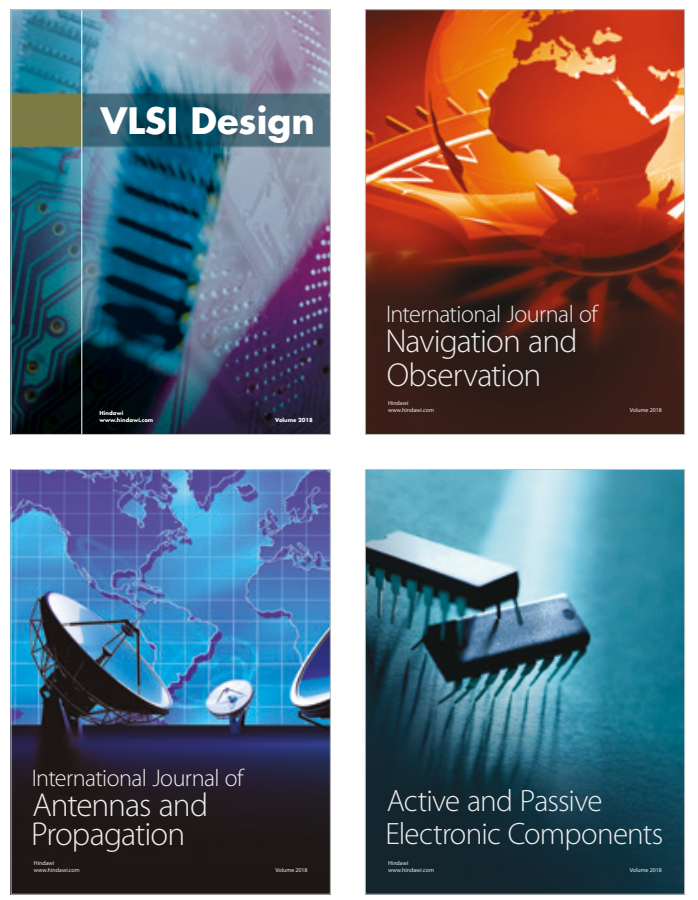
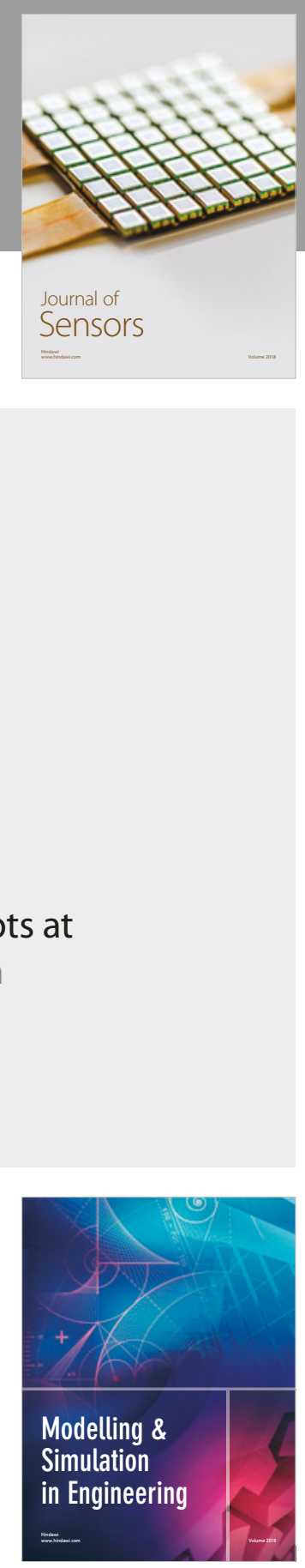

\section{Advances \\ Multimedia}
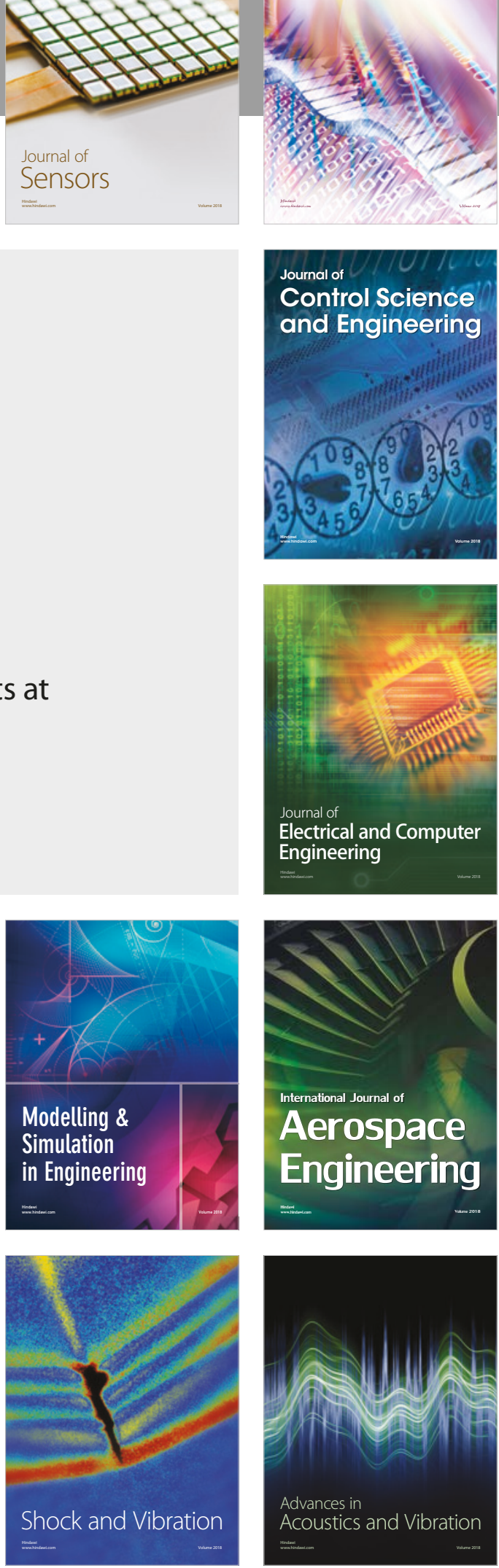